\title{
Incidence of catheter-related complications among Japanese patients with central venous catheters as well as patients with short bowel syndrome
}

This article was published in the following Dove Press journal: Clinical and Experimental Gastroenterology

\author{
Vicki K Wing' \\ Yan Song ${ }^{2}$ \\ Cheryl Xiang ${ }^{2}$ \\ Xinyue Liu $^{3}$ \\ Dendy Macaulay ${ }^{3}$ \\ Maria Ponsillo ${ }^{4}$ \\ William A Blumentals ${ }^{5}$ \\ 'Department of Epidemiology, \\ Harvard T.H. Chan School of Public \\ Health, Boston, MA, USA; ${ }^{2}$ Analysis \\ Group, Boston, MA, USA; ${ }^{3}$ Analysis \\ Group, New York, NY, USA; ${ }^{4}$ Shire, \\ Cambridge, MA, USA; ${ }^{5}$ Shire, \\ Lexington, MA, USA
}

\begin{abstract}
Purpose: Short bowel syndrome (SBS) is a serious rare disorder that is usually managed with parenteral nutrition. Central venous catheter (CVC)-related complications are known to occur, but their incidence rates (IRs) in Japan are unknown. The aim of this study was to estimate the incidence of complications in Japanese patients with CVCs, including patients with SBS using CVCs.
\end{abstract}

Patients and methods: A retrospective cohort study in 64,817 patients with CVCs, including 81 patients with SBS, between April 2008 and October 2016 using a claims database in Japan was conducted. IRs of complications were calculated as total events divided by total catheterdays among all patients with CVCs and among patients with SBS.

Results: The majority ( $>90 \%$ ) of patients in the CVC and SBS cohorts were $\geq 18$ years old. Overall, IRs of any type of complication were numerically higher in patients with SBS compared with all patients with CVCs (2.68 vs 1.95 cases per 1,000 catheter-days, respectively). Among patients with SBS, septicemia, infection, and inflammatory reaction were the only complications observed. The complications with the highest incidence were catheter-related bloodstream infections (CRBSIs) in both the overall CVC cohort and the SBS cohort with IRs of 1.35 and 2.68 cases per 1,000 catheter-days, respectively. The IR of any CVC-related complication was numerically higher in patients with SBS with cancer vs without cancer (3.44 vs 1.86 cases per 1,000 catheter-days, respectively).

Conclusion: Our study quantifies the incidence of complications in patients with CVCs, including those with SBS, in Japan.

Keywords: database, epidemiology, prevalence, retrospective

\section{Introduction}

Short bowel syndrome (SBS) is a serious rare condition that not only results from massive surgical resection but also can be caused by a congenital defect or diseaseassociated loss of absorption. Clinically, it is characterized by the inability to maintain protein energy, fluid, electrolyte, or micronutrient balances on a conventionally accepted, normal diet. ${ }^{1}$ In infants, common causes of SBS include necrotizing enterocolitis, midgut volvulus, intestinal atresia, and gastroschisis. ${ }^{2}$ In adults, common causes of SBS include unanticipated complications following surgery, cancer, mesenteric vascular disease, and Crohn's disease..$^{3-5}$ The prevalence of SBS is unknown in most countries. Older estimates suggest two to three cases per million in Europe; ${ }^{6,7}$ however, estimates can vary widely between countries. For example, in Sweden, prevalence is estimated to be 44 people per million. ${ }^{8}$ The prevalence and incidence of SBS are unknown for the Japanese population and have not been estimated.
Correspondence: William A Blumentals Shire, 300 Shire Way, Lexington, MA 0242I, USA

$\mathrm{Tel}+\mathrm{I} 78 \mathrm{I} 3867047$

Fax +16177686410

Email wblumentals@shire.com 
Because SBS can lead to malnutrition and dehydration, parenteral support (PS: parenteral nutrition and/or intravenous fluids) is the accepted life-sustaining standard of care for this condition. ${ }^{9}$ Despite the availability of treatment, survival rates for SBS have been shown to decline over time, ${ }^{10,11}$ which may, in part, be due to central venous catheter (CVC)-related complications. ${ }^{12}$ The aim of this study was to determine the incidence rate (IR) of CVC-related complications among all patients with CVCs and among patients with SBS in Japan.

\section{Patients and methods}

We conducted a retrospective cohort study to estimate the IRs of complications in patients with CVC insertions in Japan. Data were obtained from the Medical Data Vision (MDV) (Tokyo, Japan) database, ${ }^{13,14}$ which is a hospital claims database containing medical records and claims data of more than 14.4 million patients, representing more than $10 \%$ of the Japanese population. Because this study only used de-identified data, approval from an institutional review board or ethics committee was not necessary for the conduct of this study.

\section{Study population}

Patients were identified in the database with at least one record of CVC insertion between April 2008 and October 2016. The index date was defined as the first CVC insertion. Patients were required to have at least one inpatient or outpatient (ie, outpatient services received in hospitals covered by MDV) record in the 180-day period before the index date. Patients with catheter-related complications or hemodialysis catheter insertion in the 180-day pre-index period were excluded from the study. The SBS cohort was defined as patients having at least one diagnosis of SBS before the index date and evidence of PS. SBS was identified in the database using the Japanese disease code for short gut syndrome. Two subcohorts were identified: patients with SBS with at least one malignant neoplasm diagnosis (SBS cancer) and patients with SBS without any diagnosis of malignant neoplasm (SBS no cancer) before the index date (Figure 1).

\section{IR estimates}

Patients were followed from the index date until the earliest of the following: the onset of a complication of interest, CVC removal (last CVC injection after the first CVC insertion but before any subsequent CVC insertions), or the last date of activity in the MDV database. In patients with multiple catheter insertion records, only the first qualifying insertion record was counted as the index date for the calculation of the IR of study outcomes (ie, subsequent CVC insertion after the first observed one was not counted for the device time).

\section{Definitions}

Complications of interest included intracranial hemorrhage; unspecified hemorrhage; hemorrhage complicating a procedure; arterial embolism and thrombosis; phlebitis and thrombophlebitis; pulmonary embolism and infarction; occlusion and stenosis of precerebral arteries; occlusion of cerebral arteries; transient cerebral ischemia; septicemia; bacteremia; infection and inflammatory reaction due to other internal vascular device, implant, and/or graft; and mechanical complication of other vascular device, implant, and/or graft.

A list of ICD, ninth revision, codes of the complications was obtained from a published claims study in the USA. ${ }^{15}$ The corresponding ICD-10 codes were then identified and translated to the Japan disease codes. Because the Japan coding system was more detailed than the ICD- 10 coding system, the disease codes were further screened to exclude the codes that were not relevant to the diagnosis of interest. The first or only occurrence of any of the above mentioned complications was defined as an outcome and used for the IR calculation of the "any complication" category. In patients with $\geq 1$ complication of the same type, the first occurrence of that complication was included in the IR calculation for specific types of events. In patients with multiple complication events of different types, the first occurrence of each distinct complication was used for the IR calculation of specific event types.

\section{Statistical analyses}

Because of the sample size, the study analysis was not sufficiently powered to determine the statistical significance of outcomes; therefore, we used descriptive analysis summarizes the data. Patient characteristics at the time of the first CVC insertion were summarized among patients in each cohort. Baseline characteristics included age (with categories of $0-1$, $2-17,18-64$, and $\geq 65$ years), sex, and duration of first catheter placement (with time periods of $<30,30-<90,90-179$, and 180-364 days).

IRs were calculated as the total number of complication events that occurred within the defined catheter placement period divided by the sum of the catheter-days at risk during the period of catheter placement and expressed per 1,000 catheter-days. The $95 \% \mathrm{CI}$ of the IR was calculated based on normal approximation, under the assumption that the number of events follows a Poisson distribution for the overall CVC 


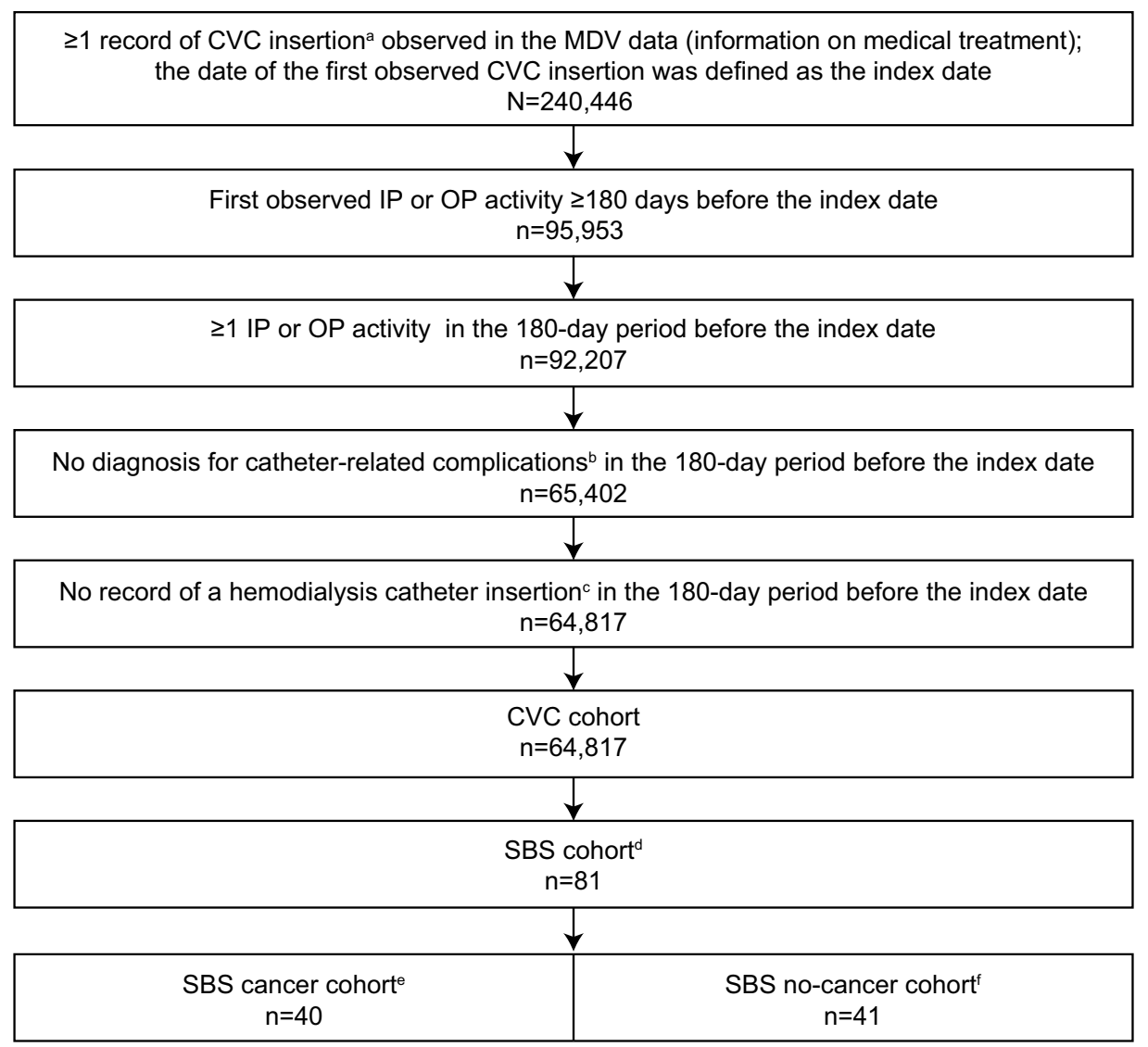

Figure I Flowchart of sample selection.

Notes: ${ }^{a}$ CVC insertion was identified via Kubun codes G005-2 or K6I8. ${ }^{b}$ Complications were identified via ICD-9-CM codes (mapped to ICD-I0 codes) ${ }^{15}$ cHemodialysis catheter insertion was identified via Kubun code K6I0-3. 'The SBS cohort was defined as having $\geq 1$ diagnosis of SBS before the index date and having received parenteral nutrition after the last diagnosis of SBS. ${ }^{\mathrm{e}}$ The SBS cancer cohort was defined as having $\geq 1$ diagnosis of malignant neoplasm before the index date. ${ }^{\mathrm{T}}$ The SBS no-cancer cohort was defined as having no diagnosis of malignant neoplasm before the index date.

Abbreviations: CVC, central venous catheter; ICD-9-CM, ICD, ninth revision, clinical modification; ICD-I0, ICD, tenth revision; IP, inpatient; MDV, Medical Data Vision; OP, outpatient; SBS, short bowel syndrome.

cohort and the two subcohorts (patients with SBS with and without a diagnosis of malignant neoplasm).

\section{Results}

Overall, 64,817 patients (mean \pm SD age, $73.7 \pm 14.5$ years; male, $57.8 \%$ ) were selected into the CVC cohort as summarized in Table 1. Within the CVC cohort, 81 patients (age, $59.2 \pm 21.1$ years; men, $61.7 \%$ ) had SBS and were placed in the SBS cohort. Within the SBS cohort, 40 patients (age, $67.2 \pm 14.7$ years; men, $65.0 \%$ ) were in the cancer cohort and 41 (age, $51.5 \pm 23.6$ years; men, 58.5\%) were in the nocancer cohort. The mean duration of first catheter placement was numerically lower in the CVC cohort compared with the overall SBS cohort (16.9 vs 28.8 days). Within the SBS cohort, mean duration of first catheter placement was slightly higher in the cancer cohort compared with the no-cancer cohort (30.8 vs 26.8 days).
IRs of complications are listed in Table 2. The IR (95\% CI) per 1,000 catheter-days for any type of complication was $1.95(1.87,2.03)$ cases for CVC patients overall and 2.68 $(1.20,5.97)$ cases for patients with SBS. Among patients with SBS, the IR per 1,000 catheter-days for any complication was $3.44(1.29,9.16)$ cases in patients with cancer and $1.86(0.47,7.45)$ cases for the no-cancer cohort. Similar to the rates for any complication, the incidence of septicemia was $1.35(1.28,1.42)$ cases among CVC patients overall and $2.68(1.20,5.97)$ cases among patients with SBS. Within the SBS cohort, IRs for septicemia were identical to the rates for any complication in both the SBS cancer and SBS no-cancer cohorts. In the CVC cohort, the IR of each of the remaining complications of interest was $<1.00$ case per 1,000 catheterdays, ranging between 0.005 (mechanical complication) and 0.18 (phlebitis and thrombophlebitis). No other complications were observed in the SBS no-cancer cohort, but an IR 
Table I Baseline characteristics ${ }^{\mathrm{a}}$

\begin{tabular}{|c|c|c|c|c|}
\hline & \multirow{2}{*}{$\begin{array}{l}\text { CVC cohort } \\
(N=64,8 \mid 7)\end{array}$} & \multicolumn{3}{|l|}{ SBS cohort } \\
\hline & & Overall $(n=81)$ & Cancer $(n=40)$ & No cancer $(n=4 I)$ \\
\hline \multicolumn{5}{|c|}{ Age at the index date, years } \\
\hline Mean (SD) & $73.7(14.5)$ & $59.2(21.1)$ & $67.2(14.7)$ & $5 \mathrm{I} .5(23.6)$ \\
\hline Q1, median, Q3 & $67,76,84$ & $48,65,75$ & $61,69,79$ & $37,54,67$ \\
\hline \multicolumn{5}{|c|}{ Age range, years, $\mathrm{n}(\%)$} \\
\hline $0-1$ & $109(0.2)$ & $\mathrm{I}(\mathrm{I} .2)$ & $0(0.0)$ & $\mathrm{I}(2.4)$ \\
\hline $2-17$ & $392(0.6)$ & $4(4.9)$ & $0(0.0)$ & $4(9.8)$ \\
\hline $18-64$ & $|2,56|(19.4)$ & $35(43.2)$ & $12(30.0)$ & $23(56.1)$ \\
\hline$\geq 65$ & $51,755(79.8)$ & $4 I(50.6)$ & $28(70.0)$ & $13(31.7)$ \\
\hline Male sex, $\mathrm{n}(\%)$ & $37,443(57.8)$ & $50(61.7)$ & $26(65.0)$ & $24(58.5)$ \\
\hline \multicolumn{5}{|c|}{ Duration of the first catheter placement, days ${ }^{b}$} \\
\hline Mean (SD) & $16.9(23.9)$ & $28.8(39.2)$ & $30.8(31.9)$ & $26.8(45.5)$ \\
\hline Q1, median, Q3 & $3,11,22$ & $8,20,34$ & $9,22,39$ & $7,16,31$ \\
\hline \multicolumn{5}{|c|}{ Duration range, $\mathrm{n}(\%)$} \\
\hline$<30$ & $54,468(84.0)$ & $53(65.4)$ & $25(62.5)$ & 28 (68.3) \\
\hline $30-<90$ & $9,430(14.5)$ & $23(28.4)$ & II (27.5) & $12(29.3)$ \\
\hline $90-179$ & $778(I .2)$ & $4(4.9)$ & $4(10.0)$ & $0(0.0)$ \\
\hline $180-364$ & $120(0.2)$ & $\mathrm{I}(\mathrm{I} .2)$ & $0(0.0)$ & I (2.4) \\
\hline
\end{tabular}

Notes: ${ }^{a}$ The baseline period was defined as the 180 days immediately preceding the index date. ${ }^{b}$ Duration of the first catheter placement was time from the first CVC insertion (index date) to last injection before the second CVC insertion; gaps $\leq 30$ days were allowed between the first CVC insertion and the first injection as well as two consecutive injections.

Abbreviations: CVC, central venous catheter; QI, 25th percentile; Q3, 75th percentile; SBS, short bowel syndrome.

Table 2 IRs of complications ${ }^{\mathrm{a}}$

\begin{tabular}{|c|c|c|c|c|}
\hline \multirow{2}{*}{$\begin{array}{l}\text { Type of complication, } \\
\text { IR ( } 95 \% \mathrm{CI})\end{array}$} & \multirow{2}{*}{$\begin{array}{l}\text { Overall CVC } \\
\text { cohort } \\
(\mathrm{N}=64,8 \mid 7)\end{array}$} & \multicolumn{3}{|l|}{ SBS cohort } \\
\hline & & $\begin{array}{l}\text { Overall } \\
(n=8 I)\end{array}$ & $\begin{array}{l}\text { Cancer } \\
(n=40)\end{array}$ & No cancer $(n=4 I)$ \\
\hline Any complication & $1.95(1.87,2.03)$ & $2.68(1.20,5.97)$ & $3.44(1.29,9.16)$ & $\mathrm{I} .86(0.47,7.45)$ \\
\hline Septicemia & $1.35(1.28,1.42)$ & $2.68(1.20,5.97)$ & $3.44(1.29,9.16)$ & $\mathrm{I} .86(0.47,7.45)$ \\
\hline Phlebitis and thrombophlebitis & $0.18(0.15,0.20)$ & 0.00 & 0.00 & 0.00 \\
\hline Infection and inflammatory reaction ${ }^{\mathrm{b}}$ & $0.16(0.14,0.18)$ & $0.43(0.06,3.05)$ & $0.8 \mathrm{I}(0 . \mathrm{II}, 5.77)$ & 0.00 \\
\hline Bacteremia & $0.09(0.08,0.1 \mathrm{I})$ & 0.00 & 0.00 & 0.00 \\
\hline Arterial embolism and thrombosis & $0.07(0.05,0.08)$ & 0.00 & 0.00 & 0.00 \\
\hline Hemorrhage, unspecified & $0.05(0.04,0.07)$ & 0.00 & 0.00 & 0.00 \\
\hline Intracranial hemorrhage & $0.04(0.03,0.05)$ & 0.00 & 0.00 & 0.00 \\
\hline Pulmonary embolism and infarction & $0.03(0.02,0.04)$ & 0.00 & 0.00 & 0.00 \\
\hline Hemorrhage complicating a procedure & $0.02(0.02,0.03)$ & 0.00 & 0.00 & 0.00 \\
\hline Transient cerebral ischemia & $0.02(0.01,0.03)$ & 0.00 & 0.00 & 0.00 \\
\hline Occlusion of cerebral arteries & $0.02(0.01,0.02)$ & 0.00 & 0.00 & 0.00 \\
\hline Occlusion and stenosis of precerebral arteries & $0.02(0.01,0.02)$ & 0.00 & 0.00 & 0.00 \\
\hline Mechanical complication ${ }^{c}$ & $0.005(0.00,0.01)$ & 0.00 & 0.00 & 0.00 \\
\hline
\end{tabular}

Notes: ${ }^{2}$ The number of complications per I,000 catheter-days and $95 \% \mathrm{Cl}$ were reported; days at risk for each complication were time from the first CVC insertion (index date) to the complication or last injection before the second CVC insertion; gaps $\leq 30$ days were allowed between the first CVC insertion and the first injection as well as two consecutive injections. IIffection and inflammatory reaction includes reactions due to other internal vascular device, implant, and graft. cMechanical complication includes complications of other vascular device, implant, and graft.

Abbreviations: CVC, central venous catheter; IR, incidence rate; SBS, short bowel syndrome.

$(95 \% \mathrm{CI})$ of $0.81(0.11,5.77)$ cases of infection and inflammatory reaction per 1,000 catheter-days was observed in the SBS cancer cohort.

When stratified by age group, the IR for any complication and septicemia was 2.70 and 2.30 cases, respectively, in CVC patients aged $\leq 18$ years and 1.94 and 1.34 cases, respectively, in CVC patients aged $\geq 18$ years (Table 3 ).
Furthermore, a numerically higher IR per 1,000 catheter-days was also observed in those aged $\leq 18$ years for bacteremia ( 0.22 vs 0.09 cases), arterial embolism and thrombosis ( 0.23 vs 0.07 cases), and occlusion of cerebral arteries ( $0.11 \mathrm{vs}$ 0.01 cases). However, it is important to note that there was a smaller sample size of patients with $\mathrm{CVC}$ in the younger group $(n=501)$ compared with the older group $(n=64,316)$. 
Table 3 IRs of complications by age group ${ }^{a}$

\begin{tabular}{|c|c|c|c|c|}
\hline \multirow[t]{2}{*}{ IR (95\% Cl) } & \multirow[t]{2}{*}{ Overall CVC cohort } & \multicolumn{3}{|l|}{ SBS cohort ch $^{\mathbf{b}}$} \\
\hline & & Overall & Cancer ${ }^{c}$ & No cancer ${ }^{d}$ \\
\hline$<18$ years old & $\mathrm{n}=50 \mathrm{I}$ & $\mathrm{n}=5$ & $\mathrm{n}=0$ & $n=5$ \\
\hline Any complication & $2.70(1.76,4.15)$ & 0.00 & & 0.00 \\
\hline Septicemia & $2.30(1.45,3.64)$ & 0.00 & & 0.00 \\
\hline Phlebitis and thrombophlebitis & 0.00 & 0.00 & & 0.00 \\
\hline Infection and inflammatory reaction ${ }^{\mathrm{e}}$ & 0.00 & 0.00 & & 0.00 \\
\hline Bacteremia & $0.22(0.06,0.89)$ & 0.00 & & 0.00 \\
\hline Arterial embolism and thrombosis & $0.23(0.06,0.92)$ & 0.00 & & 0.00 \\
\hline Hemorrhage, unspecified & 0.00 & 0.00 & & 0.00 \\
\hline Intracranial hemorrhage & 0.00 & 0.00 & & 0.00 \\
\hline Pulmonary embolism and infarction & 0.00 & 0.00 & & 0.00 \\
\hline Hemorrhage complicating a procedure & 0.00 & 0.00 & & 0.00 \\
\hline Transient cerebral ischemia & 0.00 & 0.00 & & 0.00 \\
\hline Occlusion of cerebral arteries & $0.11(0.02,0.79)$ & 0.00 & & 0.00 \\
\hline Occlusion and stenosis of precerebral arteries & 0.00 & 0.00 & & 0.00 \\
\hline Mechanical complication $^{f}$ & 0.00 & 0.00 & & 0.00 \\
\hline$\geq 18$ years old & $\mathrm{n}=64,316$ & $\mathrm{n}=76$ & $\mathrm{n}=40$ & $\mathrm{n}=36$ \\
\hline Any complication & $1.94(1.86,2.03)$ & $2.77(1.24,6.17)$ & $3.44(1.29,9.16)$ & $1.99(0.50,7.97)$ \\
\hline Septicemia & $\mathrm{I} .34(\mathrm{I} .28, \mathrm{I} .42)$ & $2.77(1.24,6.17)$ & $3.44(1.29,9.16)$ & $1.99(0.50,7.97)$ \\
\hline Phlebitis and thrombophlebitis & $0.18(0.15,0.21)$ & 0.00 & 0.00 & 0.00 \\
\hline Infection and inflammatory reaction ${ }^{\mathrm{e}}$ & $0.16(0.14,0.18)$ & $0.44(0.06,3.15)$ & $0.8 \mathrm{I}(0.1 \mathrm{I}, 5.77)$ & 0.00 \\
\hline Bacteremia & $0.09(0.08,0.1 \mathrm{I})$ & 0.00 & 0.00 & 0.00 \\
\hline Arterial embolism and thrombosis & $0.07(0.05,0.08)$ & 0.00 & 0.00 & 0.00 \\
\hline Hemorrhage, unspecified & $0.05(0.04,0.07)$ & 0.00 & 0.00 & 0.00 \\
\hline Intracranial hemorrhage & $0.04(0.03,0.05)$ & 0.00 & 0.00 & 0.00 \\
\hline Pulmonary embolism and infarction & $0.03(0.02,0.04)$ & 0.00 & 0.00 & 0.00 \\
\hline Hemorrhage complicating a procedure & $0.02(0.02,0.04)$ & 0.00 & 0.00 & 0.00 \\
\hline Transient cerebral ischemia & $0.02(0.01,0.03)$ & 0.00 & 0.00 & 0.00 \\
\hline Occlusion of cerebral arteries & $0.01(0.01,0.02)$ & 0.00 & 0.00 & 0.00 \\
\hline Occlusion and stenosis of precerebral arteries & $0.02(0.01,0.03)$ & 0.00 & 0.00 & 0.00 \\
\hline Mechanical complication ${ }^{f}$ & $0.005(0.002,0.01)$ & 0.00 & 0.00 & 0.00 \\
\hline
\end{tabular}

Notes: ${ }^{2}$ The number of complications per I,000 catheter-days and $95 \% \mathrm{Cl}$ were reported; days at risk for each complication were time from the first $\mathrm{CVC}$ insertion (index date) to the complication or last injection before the second CVC insertion; gaps $\leq 30$ days were allowed between the first CVC insertion and the first injection as well as two consecutive injections. ${ }^{b}$ The SBS cohort was defined as having $\geq 1$ diagnosis of SBS before the index date and having received parenteral nutrition after the last diagnosis of SBS. 'The SBS cancer cohort was defined as having $\geq 1$ diagnosis of malignant neoplasm before the index date. ${ }^{\mathrm{C}}$ The SBS no-cancer cohort was defined as having no diagnosis of malignant neoplasm before the index date. Infection and inflammatory reaction includes reactions due to other internal vascular device, implant, and graft. 'Mechanical complication includes complications of other vascular device, implant, and graft.

Abbreviations: CVC, central venous catheter; IR, incidence rate; SBS, short bowel syndrome.

Among patients with SBS ( $\mathrm{n}=5$, no-cancer cohort), no complications were observed in patients aged $<18$ years.

\section{Discussion}

To the best of our knowledge, this study is the first to estimate the IR of CVC-related complications among patients with SBS in Japan. However, the Japanese incidence of CVC-related complication has been reported in other contexts. A study conducted by Shirotani et a ${ }^{16}$ evaluated the incidence of CVCrelated complications among patients receiving home PS over 16 years. In this population sample, $14.7 \%$ had SBS. Overall, $38.2 \%$ of patients experienced a CVC-related complication at a rate of 0.29 cases per catheter-year among patients with an external tunneled catheter and 0.66 cases per catheter-year among patients with an implanted port. Of these complications, $26.5 \%$ were catheter-related bloodstream infections (CRBSIs), $5.9 \%$ were mechanical problems, $2.9 \%$ were CVC or port occlusions, $1.5 \%$ were central vein thrombosis, and $1.5 \%$ were accidental removals. In another study conducted in Japan, $2.9 \%$ of neonates who had a CVC insertion experienced CVC-related complications, of which $1.6 \%$ were due to CRBSIs. ${ }^{17}$ Published data regarding IR of CVC-related complications in patients with SBS from other countries are limited (Table 4). Unfortunately, differences in study designs and how catheter-related complications were defined make it difficult to directly compare these studies with ours.

In our study, the IR of any CVC-related complication was 1.95 cases per 1,000 catheter-days for the overall CVC 
Table 4 Published IRs of catheter-related complications

\begin{tabular}{|c|c|c|c|c|c|c|}
\hline Study & Population & $\begin{array}{l}\text { Setting; study } \\
\text { design }\end{array}$ & $\begin{array}{l}\text { Sample } \\
\text { size, } n\end{array}$ & $\begin{array}{l}\text { IRs among patients } \\
\text { with SBS, }^{\mathrm{a}} \text { per I,000 } \\
\text { catheter-days }\end{array}$ & Strengths & Weaknesses \\
\hline $\begin{array}{l}\text { Current } \\
\text { study }\end{array}$ & $\begin{array}{l}\text { Patients using CVCs in } \\
\text { Japan }\end{array}$ & $\begin{array}{l}\text { Multicenter database; } \\
\text { retrospective cohort }\end{array}$ & $\begin{array}{l}\text { Total, 64,8I7; } \\
\text { SBS cohort, 8I }\end{array}$ & $\begin{array}{l}\text { Any CVC-related } \\
\text { complication, } 2.68 ; \\
\text { CRBSIs, } 2.68\end{array}$ & $\begin{array}{l}\text { Multicenter, large } \\
\text { CVC sample }\end{array}$ & $\begin{array}{l}\text { Small SBS } \\
\text { sample size }\end{array}$ \\
\hline $\begin{array}{l}\text { Brandt } \\
\text { et } \text { al }^{18}\end{array}$ & $\begin{array}{l}\text { Patients with intestinal } \\
\text { failure obtaining home } \\
\text { parenteral nutrition in } \\
\text { Denmark }\end{array}$ & $\begin{array}{l}\text { Single-center } \\
\text { database; } \\
\text { retrospective cohort }\end{array}$ & $\begin{array}{l}\text { Total, 508; SBS } \\
\text { cohort, } 307\end{array}$ & $\begin{array}{l}\text { Any CVC-related } \\
\text { complication, } 2.54 ; \\
\text { CRBSIs, I.45 }\end{array}$ & $\begin{array}{l}\text { Large SBS sample, } \\
\text { long study period }\end{array}$ & Single center \\
\hline Wu et $a^{19}$ & $\begin{array}{l}\text { Patients with SBS who } \\
\text { received home parenteral } \\
\text { nutrition for } \geq 2 \text { years in } \\
\text { China }\end{array}$ & $\begin{array}{l}\text { Hospital }(n=I) ; \\
\text { retrospective cohort }\end{array}$ & $\begin{array}{l}\text { Total, 47; SBS } \\
\text { cohort, } 47\end{array}$ & $\begin{array}{l}\text { Catheter sepsis, } 0.85 ; \\
\text { catheter occlusion, } 0.16\end{array}$ & Long study period & $\begin{array}{l}\text { Single center, } \\
\text { small sample } \\
\text { size }\end{array}$ \\
\hline $\begin{array}{l}\text { Napalkov } \\
\text { et } \text { al }^{15}\end{array}$ & $\begin{array}{l}\text { Patients using CVCs } \\
\text { during the first } 90 \text { days of } \\
\text { insertion in the USA }\end{array}$ & $\begin{array}{l}\text { i3 InVision } \\
\text { claims database; } \\
\text { retrospective cohort }\end{array}$ & $\begin{array}{l}\text { Total, } 16,721 ; \\
\text { catheter } \\
\text { placement }<90 \\
\text { days: } 5,060\end{array}$ & $\begin{array}{l}\text { Any CVC-related } \\
\text { complication, } 6.00^{\mathrm{a}} \text {; } \\
\text { CRBSI, } 4.0 \mathrm{I}^{\mathrm{a}}\end{array}$ & Large sample & $\begin{array}{l}\text { Not specific } \\
\text { for patients } \\
\text { with SBS }\end{array}$ \\
\hline
\end{tabular}

Note: aNapalkov et al' ${ }^{15}$ reported that IR is not specific to patients with SBS.

Abbreviations: CRBSI, catheter-related bloodstream infection; CVC, central venous catheter; IR, incidence rate; SBS, short bowel syndrome.

cohort and 2.68 cases per 1,000 catheter-days for the SBS cohort. In a US retrospective cohort analysis, the IR for the overall CVC cohort was 6.00 cases based on the first 90 days of catheter placement. ${ }^{15}$ Although a direct comparison cannot be made, the IR reported in a Danish study of patients with SBS who received home PS from one tertiary referral center 2.54 cases per 1,000 catheter-days. ${ }^{18}$ Septicemia was reported as the most common type of complication with an IR of 2.68 cases per 1,000 catheter-days. This finding is similar to a Chinese study, in which sepsis was also reported as the most common CVC-related complication, with an IR of 0.85 cases per 1,000 catheter-days. ${ }^{19}$ The Chinese study differed in that data were collected from a single center, diminishing its generalizability, and the authors were interested in patients with nonmalignant SBS and in complications associated with the long-term ( $\geq 2$ years) catheter use.

The use of claims data is not without limitations, and it is important to emphasize that this study is not without such limitations. The lack of clinical details in claims databases makes it possible that some patient data were missing or patients were misdiagnosed. The MDV database, however, has been previously validated for venous thromboembolism and bleeding events, with positive predictive values $>70 \%$, increasing confidence in our choice of database used for the study. ${ }^{20}$ The MDV database only included tertiary hospitals and thus may not have included patients with less severe disease, thereby affecting generalizability. In addition, the database does not cover the patients' entire claims history, because they may have received medical services outside the facilities included in the MDV database. The procedure codes used to describe CVC-related complications did not include a level of specificity to distinguish between catheter types (eg, non-tunneled, subcutaneously tunneled, totally implanted, and peripherally inserted central catheter). Although the sample size precluded a formal statistical comparison, the study still provides meaningful data that contribute to our understanding of CVC-related complications in an SBS population. More robust results and conclusions may occur with the synthesis of data across studies and even prospective collection of data in patients with SBS.

\section{Conclusion}

The IRs observed in our study are informative regarding the incidence of CVC-related complications in patients with SBS in Japan. Further research on the incidence of CVCrelated complications is warranted given the paucity of data in patients with SBS and the importance that such complications have on patients' quality of life.

\section{Abbreviations}

CRBSIs, catheter-related bloodstream infections; CVC, central venous catheter; IR, incidence rate; MDV, Medical Data Vision; PS, parenteral support (parenteral nutrition and/or intravenous fluids); SBS, short bowel syndrome. 


\section{Acknowledgments}

This study was funded by Shire Human Genetic Therapies, Inc. (Lexington, MA, USA). Editorial support was provided by Complete Healthcare Communications, LLC, a CHC Group Company (North Wales, PA, USA), and the publication was funded by Shire International $\mathrm{GmbH}$, Zug, Switzerland.

\section{Author contributions}

All authors contributed to data analysis, drafting and revising the article, gave final approval of the version to be published, and agree to be accountable for all aspects of the work.

\section{Disclosure}

Vicki K Wing served as an intern with Shire. Yan Song, Cheryl Xiang, Xinyue Liu, and Dendy Macaulay are employees of Analysis Group, which has received consultancy fees from Shire. William A Blumentals and Maria Ponsillo were employees of Shire at the time this study was conducted and the manuscript was written. The authors report no other conflicts of interest in this work.

\section{References}

1. O’Keefe SJ, Buchman AL, Fishbein TM, Jeejeebhoy KN, Jeppesen PB, Shaffer J. Short bowel syndrome and intestinal failure: consensus definitions and overview. Clin Gastroenterol Hepatol. 2006;4(1):6-10.

2. Duro D, Kamin D, Duggan C. Overview of pediatric short bowel syndrome. J Pediatr Gastroenterol Nutr. 2008;47(Suppl 1):S33-S36.

3. Fishbein TM, Schiano T, Leleiko N, et al. An integrated approach to intestinal failure: results of a new program with total parenteral nutrition, bowel rehabilitation, and transplantation. J Gastrointest Surg. 2002;6(4):554-562.

4. Thompson JS, DiBaise JK, Iyer KR, Yeats M, Sudan DL. Postoperative short bowel syndrome. J Am Coll Surg. 2005;201(1):85-89.

5. Thompson JS, Iyer KR, DiBaise JK, Young RL, Brown CR, Langnas AN. Short bowel syndrome and Crohn's disease. J Gastrointest Surg. 2003;7(8):1069-1072.
6. ESPEN-Home Artificial Nutrition Working Group, Van Gossum A, Bakker H, et al. Home parenteral nutrition in adults: a multicentre survey in Europe in 1993. Clin Nutr. 1996;15(2):53-59.

7. Lennard-Jones JE. Indications and need for long-term parenteral nutrition: implications for intestinal transplantation. Transplant Proc. 1990;22(6):2427-2429.

8. Kurlberg G, Forssell H, Aly A. National registry of patients with short bowel syndrome. Transplant Proc. 2004;36(2):253-254.

9. Nightingale J, Woodward JM; Small Bowel and Nutrition Committee of the British Society of Gastroenterology. Guidelines for management of patients with a short bowel. Gut. 2006;55(Suppl 4):iv1-iv12.

10. Messing B, Crenn P, Beau P, Boutron-Ruault MC, Rambaud JC, Matuchansky C. Long-term survival and parenteral nutrition dependence in adult patients with the short bowel syndrome. Gastroenterology. 1999;117(5):1043-1050.

11. Quirós-Tejeira RE, Ament ME, Reyen L, et al. Long-term parenteral nutritional support and intestinal adaptation in children with short bowel syndrome: a 25-year experience. J Pediatr. 2004;145(2):157-163.

12. Howard L, Ashley C. Management of complications in patients receiving home parenteral nutrition. Gastroenterology. 2003;124(6):1651-1661.

13. Mahlich J, Sruamsiri R. Treatment patterns of rheumatoid arthritis in Japanese hospitals and predictors of the initiation of biologic agents. Curr Med Res Opin. 2017;33(1):101-107.

14. Sakon M, Maehara Y, Kobayashi T, et al. Economic burden of venous thromboembolism in patients undergoing major abdominal surgery. Value Health Reg Issues. 2015;6:73-79.

15. Napalkov P, Felici DM, Chu LK, Jacobs JR, Begelman SM. Incidence of catheter-related complications in patients with central venous or hemodialysis catheters: a health care claims database analysis. $B M C$ Cardiovasc Disord. 2013;13:86.

16. Shirotani N, Iino T, Numata K, Kameoka S. Complications of central venous catheters in patients on home parenteral nutrition: an analysis of 68 patients over 16 years. Surg Today. 2006;36(5):420-424.

17. Ohki Y, Maruyama K, Harigaya A, Kohno M, Arakawa H. Complications of peripherally inserted central venous catheter in Japanese neonatal intensive care units. Pediatr Int. 2013;55(2):185-189.

18. Brandt CF, Tribler S, Hvistendahl M, et al. Home parenteral nutrition in adult patients with chronic intestinal failure: catheter-related complications over 4 decades at the main Danish tertiary referral center. JPEN J Parenter Enteral Nutr. Epub 2016 Nov 15.

19. Wu G, Jiang Y, Zhu X, et al. Prevalence and risk factors for complications in adult patients with short bowel syndrome receiving long-term home parenteral nutrition. Asia Pac J Clin Nutr. 2017;26(4):591-597.

20. Yamaguchi T, Fuji T, Akagi M. The epidemiological study of venous thromboembolism and bleeding events using a Japanese healthcare database - validation study. Jpn J Drug Inform. 2015;17(2):87-93.
Clinical and Experimental Gastroenterology

\section{Publish your work in this journal}

Clinical and Experimental Gastroenterology is an international, peerreviewed, open access, online journal publishing original research, reports, editorials, reviews and commentaries on all aspects of gastroenterology in the clinic and laboratory. This journal is included on PubMed. The manuscript management system is completely online
Dovepress

and includes a very quick and fair peer-review system, which is all easy to use. Visit http://www.dovepress.com/testimonials.php to read real quotes from published authors. 